\title{
Feeding habits of a new Arctic predator: insight from full-depth blubber fatty acid signatures of Greenland, Faroe Islands, Denmark, and managed-care killer whales Orcinus orca
}

\author{
Jennifer Bourque ${ }^{1}$, Rune Dietz ${ }^{2}$, Christian Sonne ${ }^{2}$, Judy St. Leger ${ }^{3}$, Sara Iverson ${ }^{4}$, \\ Aqqalu Rosing-Asvid ${ }^{5}$, Martin Hansen ${ }^{6}$, Melissa A. McKinney ${ }^{1,7, *}$ \\ ${ }^{1}$ Wildlife and Fisheries Conservation Center, \\ Department of Natural Resources and the Environment and Center for Environmental Sciences and Engineering, University \\ of Connecticut, Storrs, CT 06269, USA \\ ${ }^{2}$ Department of Bioscience, Arctic Research Centre, Aarhus University, Roskilde 4000, Denmark \\ ${ }^{3}$ SeaWorld San Diego, Pathology, San Diego, CA 92109, USA \\ ${ }^{4}$ Department of Biology, Dalhousie University, Halifax, NS B3H 4R2, Canada \\ ${ }^{5}$ Greenland Institute of Natural Resources, Nuuk 3900, Greenland \\ ${ }^{6}$ Department of Environmental Science, Aarhus University, Roskilde 4000, Denmark
}

${ }^{7}$ Present address: Department of Natural Resource Sciences, McGill University, Sainte-Anne-de-Bellevue, QC H9X 3V9, Canada

ABSTRACT: An increasing number of North Atlantic killer whales Orcinus orca have recently been observed in sub-Arctic and Arctic seas. Within these regions, marine mammal consumption appears frequent relative to the more fish-based diet within traditional habitats. To provide insight into feeding habits of northward range-expanding killer whales, full-depth blubber fatty acid signatures from 21 free-ranging killer whales from southeast Greenland, Faroe Islands, and Denmark were compared to those of 4 managedcare killer whales, which were fed a constant, longterm fish diet. We analyzed the entire blubber layer in 10 equal-length subsections to evaluate how fatty acid stratification throughout blubber depth may influence fatty acid-based feeding evaluations. Specific fatty acid markers previously linked to marine mammal feeding in other killer whale populations were significantly higher in free-ranging killer whales relative to managed-care individuals, suggesting that marine mammals represent a time-integrated component of free-ranging killer whales' diet. Unlike the managedcare whales, fatty acid signatures were highly variable among the free-ranging killer whales, suggesting that either they are generalists or exhibit inter-individual feeding variation. All samples, regardless of origin, showed stratification of fatty acid signatures through blubber layers. Dietary fatty acids generally occurred in higher proportions and were more variable in the innermost layers for the free-ranging whales. These

*Corresponding author: melissa.mckinney@mcgill.ca

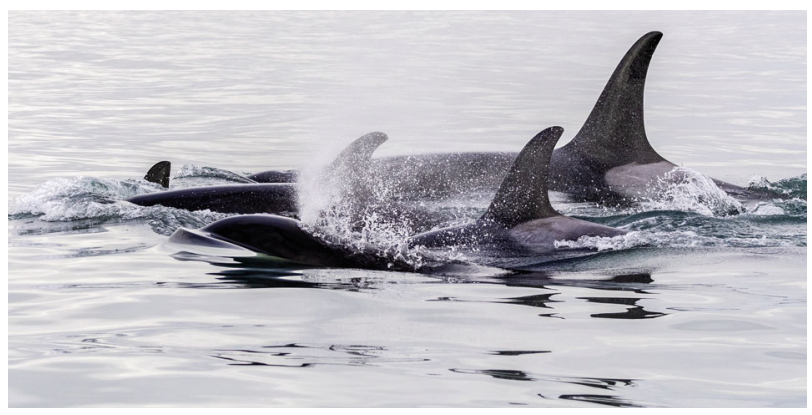

Killer whales Orcinus orca (center) that are undergoing a northward range shift are feeding on marine mammals in Greenlandic waters.

Photo: Richard Hebhardt

data suggest that superficial blubber sampling through biopsy darting may not capture fine-scale and/or short-term variation in diet, and therefore the sampling approach should be carefully considered in research using fatty acids to evaluate feeding ecology of killer whales and other cetaceans.

KEY WORDS: Arctic marine ecology - Climate change - Diet composition - Fatty acid signatures · Foraging ecology · Killer whale - Marine mammal • North Atlantic $\cdot$ Species distribution

(c) Dietz, Sonne, St. Leger, Rosing-Asvid, Hansen, and outside the USA The US Government 2018. Open Access under Creative Commons by Attribution Licence. Use, distribution and reproduction are unrestricted. Authors and original publication must be credited.

Publisher: Inter-Research · www.int-res.com 


\section{INTRODUCTION}

Sightings and hunting of killer whales Orcinus orca have become more common along the coasts of Greenland since 2008 (Statistics Greenland 2017), and killer whales have also been documented on an increasing basis in Arctic and sub-Arctic waters of eastern Canada (Higdon \& Ferguson 2009, Ferguson et al. 2010, Higdon et al. 2012). Within these areas, observations of killer whale predation on marine mammals have been reported (Ferguson et al. 2010, Higdon et al. 2012, A. Rosing-Asvid unpubl. data). Moreover, interviews conducted with wildlife hunters in Canada have suggested that marine mammals make up most, or perhaps all, of the diet of these invading killer whales (Ferguson et al. 2010). Nevertheless, observational data can be biased against predatory events of smaller size, occurring at night, during fall or winter, and those that occur below the surface of the water, and they do not provide knowledge on longer-term feeding habits (Tollit et al. 1997, Herman et al. 2005, Springer et al. 2008). Timeintegrated approaches to studying the diets of these presumably North Atlantic killer whales within Arctic and sub-Arctic regions are needed to evaluate the potential impacts of this novel predation on prey populations within Arctic ecosystems.

Ecological speciation of killer whales based on feeding specialization has been clearly demonstrated in the Northeast Pacific and may occur in the Antarctic and North Atlantic as well. Three distinct ecotypes - resident, transient, and offshore-have been identified in the Northeast Pacific (Barrett-Lennard 2000). The resident ecotype predominantly consumes fish, whereas transients principally consume marine mammals. The offshore ecotype is scarcer but has shown distinct dietary patterns from the other 2 Northeast Pacific ecotypes, apparently preying on sharks among others (Herman et al. 2005, Ford et al. 2011). Although ecotypes are less clearly defined in the North Atlantic, there are some indications of dietary specialization among populations. Two North Atlantic ecotypes have been suggested to be generalists and specialists, although neither are officially recognized (Foote et al. 2009, 2011). A more recent study by Foote et al. (2012) speculated that for North Atlantic killer whales, the generalists may in fact be comprised of individuals that show a different feeding specialization within the same population.

To better understand the feeding ecology of marine mammals inhabiting remote marine environments, ecological tracer approaches have been applied. Thus far, research on the feeding habits of North
Atlantic killer whales has used tooth wear measurements and stable isotope analysis to suggest broadscale feeding patterns (Foote et al. 2009, 2011, 2012). Foote et al. (2012) concluded, however, that stable isotope analysis alone was not sufficient to delineate diet, and further research should use fatty acid signatures and possibly organochlorine pollutant analysis. In a recent study from Iceland, Samarra et al. (2017) documented that herring-eating killer whales exhibit intra-population ecological variation, whereby individuals or groups differ in the proportional contribution of different prey items to their diet. Fine-scale (i.e. species-level) feeding estimates for marine mammals have been obtained using quantitative fatty acid signature analysis (QFASA) (Iverson et al. 2004, Bowen \& Iverson 2013). This method determines the proportion of prey consumed by an individual predator by statistically comparing the blubber fatty acids of the predator to those of the potential prey species, after accounting for predator fatty acid metabolism prior to blubber deposition using calibration coefficients (Iverson et al. 2004). Indeed, QFASA has led to high-resolution diet estimates in other marine mammals including gray seal Halichoerus grypus, Hawaiian monk seal Monachus schauinslandi, Steller sea lion Eumetopias jubatus, and harbor seal Phoca vitulina (Iverson et al. 2004, Cooper 2005, Tollit et al. 2006, Nordstrom et al. 2008). Quantitative analysis has, however, not yet been applied to evaluating the diet of killer whales.

Despite potential insight into killer whale feeding ecology, so far only qualitative comparisons of fatty acid signatures among killer whale ecotypes have been evaluated, and only for the Northeast Pacific populations. Fatty acid signatures were shown to be distinct among the 3 ecotypes found in the Northeast Pacific (Herman et al. 2005). A combination of just 5 fatty acids were needed to successfully separate the 3 ecotypes found off the coast of Alaska (Herman et al. 2005, Krahn et al. 2007). Quantitative evaluation has not been attempted, mainly for two reasons. The first barrier is the lack of calibration coefficients generated from controlled feeding trials on cetaceans, which take into account the metabolism of the predator. The second issue is that the possible impact of fatty acid variation in highly stratified cetacean blubber on quantitative diet estimates has not been evaluated in detail. Full evaluation of fatty acid profiles with blubber depth has not been performed because nearly all previous studies have been limited to blubber biopsies, which contain only the outermost blubber tissues (Krahn et al. 2004). One study on 2 Northeast Pacific killer whales, along with 8 captive 
individuals, was able to evaluate full blubber-depth profiles subdivided into 6 blubber layers (Worthy 2008). It was shown that fatty acids with less than 18 carbon atoms were found predominantly in the inner blubber layers, suggesting that these layers are metabolically more active for lipid deposition and movement; therefore, they may better represent diet profiles. How influential this variation may be on qualitative or quantitative diet assessments using fatty acid signatures is not yet known.

The aim of the present study was first to provide insight into the diets of northward-redistributing North Atlantic killer whales through full-depth blubber fatty acid analysis of 21 individuals recently sampled in Greenland, the Faroe Islands, and Denmark. Secondly, we compared the fatty acid signatures with those of 4 managed-care killer whales, which were fed long-term diets of fish. We hypothesized that readily accessible and energy-rich marine mammals are an important component of the diet of this new Arctic predator. Our third aim was to assess whether fatty acid stratification through the blubber layer may confound interpre- tations of feeding ecology based on blubber fatty acid analysis of killer whales and other cetaceans.

\section{MATERIALS AND METHODS}

\section{Sample collection}

A total of 21 free-ranging North Atlantic killer whales were opportunistically sampled between 2005 and 2014. Eighteen of the samples were collected from subsistence-harvested individuals in southeast Greenland between 2012 and 2014. The remaining samples were collected from stranded individuals; 1 from Denmark in 2005, and 2 from the Faroe Islands in 2008 (Table 1). Full-depth blubber samples were collected from the torso region of all individuals. Skin was left attached to the blubber to determine the orientation of the blubber. Location and biological data including sex/age class (fetus, neonate, sub-adult, adult female, and adult male), lengths, and stomach contents (if available) were also recorded. Subsamples of archived blubber were

Table 1. Sampling and biological information for 21 free-ranging North Atlantic killer whales sampled between 2005 and 2014 , as well as 4 managed-care killer whales (also reported in Pedro et al. 2017). ND: not determined or, in the case of stomach contents, empty; N/A: currently unavailable

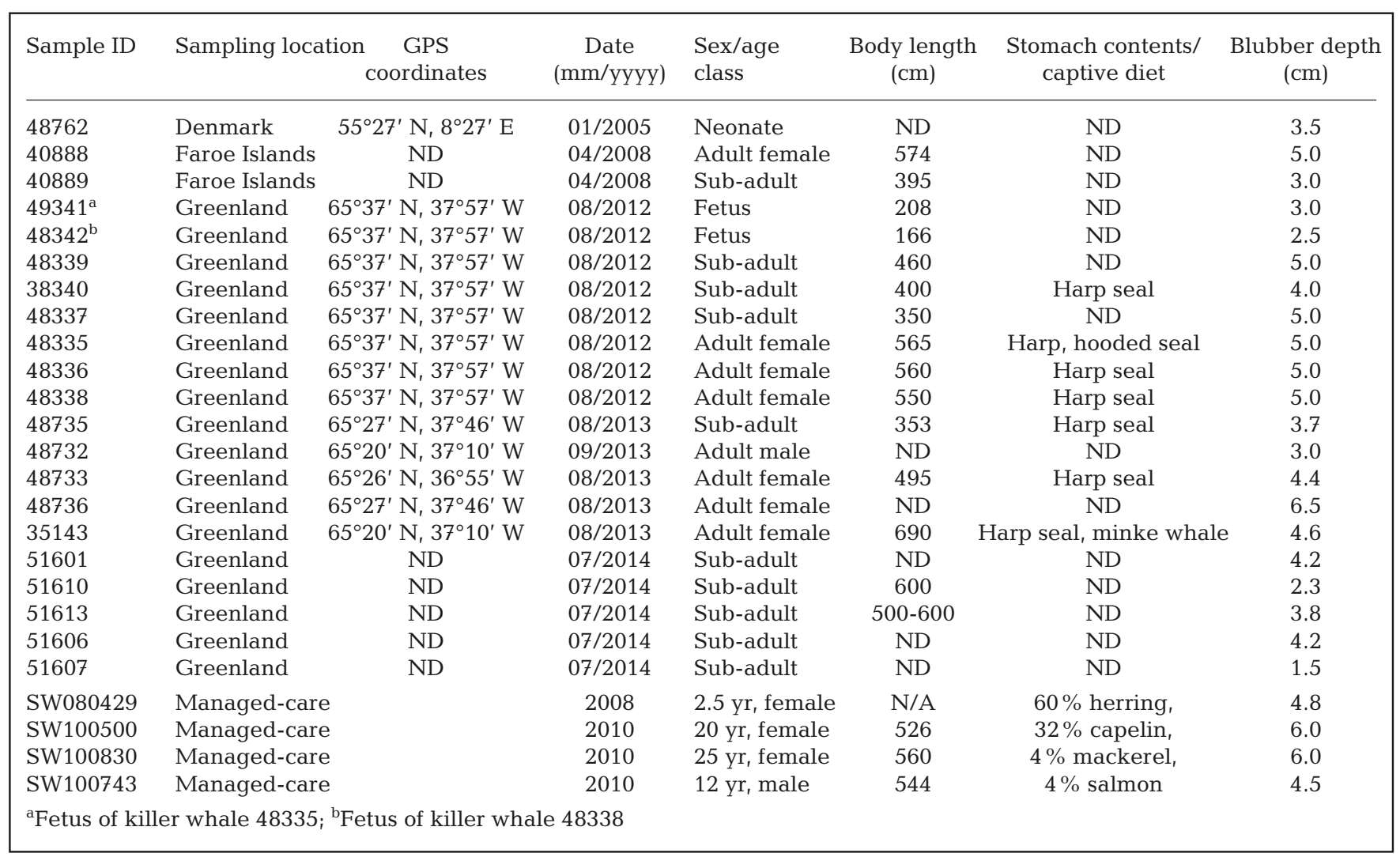


taken from 4 deceased, managed-care killer whales (1 in 2008 and 3 in 2010) housed at SeaWorld following the same specifications. The managed-care individuals were fed a constant, long-term diet consisting of roughly the same proportions of Pacific herring Clupea pallasii (60\%), capelin Mallotus villosus (32\%), Pacific mackerel Scomber japonicus (4\%), and pink salmon Oncorhynchus gorbuscha (4\%). None of the individuals suffered from pre-terminal weight loss, which could lead to differential mobilization and metabolism of individual fatty acids (Koopman et al. 2002). Samples from free-ranging and managed-care individuals were frozen $\left(-20^{\circ} \mathrm{C}\right)$ after collection and during transport and stored at $-80^{\circ} \mathrm{C}$ at the University of Connecticut from May and August 2015, respectively, until analysis in November 2015 through July 2016.

\section{Fatty acid signature analysis}

Fatty acid analysis was performed as previously described for blubber/adipose samples (Budge et al. 2006, McKinney et al. 2013). First, the sample was shaved to reveal fresh blubber. Next, to evaluate the influence of fatty acid stratification through the blubber layer (Koopman 2003, Worthy 2008), each fulldepth blubber sample was divided into 10 equallength segments, with the innermost layer (closest to the muscle) designated layer 1 and the outermost layer (closest to the skin) designated layer 10 (see Pedro et al. 2017). Lipids were quantitatively extracted via the Folch method, and lipid content (as mass \% lipid) of the sample was determined gravimetrically. Extracted fatty acids were then transesterified using the Hilditch reagent to produce fatty acid methyl esters (FAMEs). Extracts containing the FAMEs were then separated, identified, and quantified by gas chromatography with flame ionization detection (GC-FID) (Budge et al. 2006). A total of 69 fatty acids were reported as mass percent of total FAME. Each fatty acid was subsequently denoted by the nomenclature $x: y n z$, where $x$ is the length of the carbon chain, $y$ is the number of double bonds, and $z$ is the position of the first double bond from the methyl (' $n$ ') end of the chain.

\section{Quality control}

Quality control included the extraction and analysis of a standard reference material (SRM) with each batch of 12 samples. The National Institute of Stan- dards and Technology (NIST) SRM1945, pilot whale Globicephala melas blubber, was analyzed previously for 27 individual fatty acids during a NIST-led inter-laboratory comparison exercise (Kucklick et al. 2010). The SRM was run 16 times with the killer whale batches, and the relative standard deviation compared to the published values averaged $16 \%$.

\section{Statistical analysis}

Fatty acid signatures were evaluated both as (1) the blubber layer-specific signature, i.e. the mass percent of a given fatty acid in each of the blubber layers, 1 through 10, and (2) the overall full-depth signature, i.e. the mass percent of each fatty acid averaged across the 10 blubber layers, weighted by the lipid content of each layer (equivalent to the value determined from a single, full-depth sample). For descriptive statistics, each fatty acid was reported as the arithmetic mean and standard error of the mean. To meet the assumptions of the inferential statistical tests, the mass percent values were first centered logratio transformed according to the following equation: $x_{\mathrm{t}}=\log \left[x_{\mathrm{i}} / g(x)\right]$, where $x_{\mathrm{t}}$ represents the transformed value, $x_{\mathrm{i}}$ is the individual fatty acid expressed as mass percent, and $g(x)$ is the geometric mean of the fatty acid values for the sample (Aitchison 1983, Budge et al. 2008). All statistical analyses were performed in $\mathrm{R}$ (R Development Core Team 2016).

To evaluate inter-individual variation in overall (full-depth) fatty acid signatures between North Atlantic and captive killer whales, multivariate analysis of variance (MANOVA) tests were run on the 16 major fatty acids (defined as the highest mean proportions present based on the full-depth values). Additionally, a hierarchical cluster using squared Euclidean distance (Thiemann et al. 2008) was performed to visualize similarities and differences in fatty acid signatures among groups, considering geographic location and sex/age class; thus, specific groups included managed-care, Greenland adult male, Greenland adult female, Greenland sub-adult, Greenland fetus, Faroe Island adult female, Faroe Island sub-adult, and Denmark neonate. Principal component analysis (PCA) was utilized to visualize variation between managedcare and North Atlantic killer whales.

To evaluate fatty acid stratification among the blubber layers, MANOVAs were performed on the same 16 major fatty acids. A univariate ANOVA and post hoc Tukey's honestly significant difference tests were used on the fatty acids that showed significant stratification. A PCA was utilized to visualize varia- 
tion among blubber depth layers. Five variables were used to construct the PCAs in all cases in order to keep an approximate 5:1 sample:variable ratio (Stevens 1986, Tabachnick \& Fidell 1989). The chosen fatty acids were 16:1n7, 18:1n9, 20:1n9, 22:1n11, and 22:6n3, as these (1) represented major fatty acids (from 1.01 to $22.23 \%$ of total FAME), (2) have previously been considered to be 'dietary' (those that are largely present through ingestion and not through biosynthesis; Iverson et al. 2004), and/or (3) have previously been shown to distinguish fish-feeding and marine mammal-feeding killer whales in the Northeast Pacific (Herman et al. 2005).

\section{RESULTS}

\section{Fatty acid signatures of North Atlantic and managed-care killer whales}

Of the 69 fatty acids analyzed, 68 were found in one or more blubber layers of both the managed-care and free-ranging North Atlantic killer whales Orcinus orca (see Tables S1 \& S2 in the Supplement at www. int-res.com/articles/suppl/m603p001_supp.pdf) (only 8:0 was not detected). Many fatty acids only accounted for a fraction of a percent of the total FAME and were thus not included in the final analysis to avoid bias due to analytical variability at low concentration (Budge et al. 2006). In total, 16 major fatty acids were used for the analysis: 14:0, 14:1n5, 16:0, 16:1n11，16:1n9，16:1n7，18:1n11，18:1n9，18:1n7, 18:2n6, 18:3n3, 20:1n11, 20:1n9, 20:5n3, 22:1n11, and 22:6n3. Considering the single full-depth measurements, these fatty acids comprised $86 \%$ of the total FAME in the North Atlantic killer whales and $85 \%$ of the total FAME in the managed-care whales. Of these fatty acids, 18:2n6, 18:3n3, 20:1n11, 20:1n9, 20:5n3, 22:1n11, and 22:6n3 are considered 'dietary' (Iverson et al. 2004). These 7 fatty acids comprised 29 and $18 \%$ of the total FAME for the North Atlantic and managed-care killer whales, respectively.

Based on the overall full-depth blubber signature, the profile of the 16 major fatty acids showed significant differences between the North Atlantic killer whales and the managed-care group ( $p=0.003$ ) (Fig. 1). Post hoc analysis revealed that proportions of 10 of the 16 major fatty acids differed significantly. Fatty acids thought to primarily or partially be sourced de novo showed significant differences, with $14: 1 \mathrm{n} 5(\mathrm{p}=0.048), 16: 1 \mathrm{n} 7$ ( $\mathrm{p}<0.001)$, and 18:1n9 ( $\mathrm{p}=$ 0.002 ) found in significantly higher proportions in the North Atlantic whales relative to the managed-care whales, and 16:1n11 ( $\mathrm{p}=0.004)$ and 18:1n11 ( $\mathrm{p}=$ 0.002) found in significantly lower proportions. Fatty acids considered to be primarily or solely present due to dietary intake also varied, with proportions of 20:1n11 ( $<<0.001), 20: 1 \mathrm{n} 9(\mathrm{p}=0.017), 20: 5 \mathrm{n} 3$ ( $\mathrm{p}=$ $0.017), 22: 1 \mathrm{n} 11$ ( $\mathrm{p}<0.001)$, and 22:6n3 ( $\mathrm{p}=0.015)$ being significantly higher in the managed-care whales than in the free-ranging North Atlantic whales. Proportions of the essential (diet-derived) fatty acids

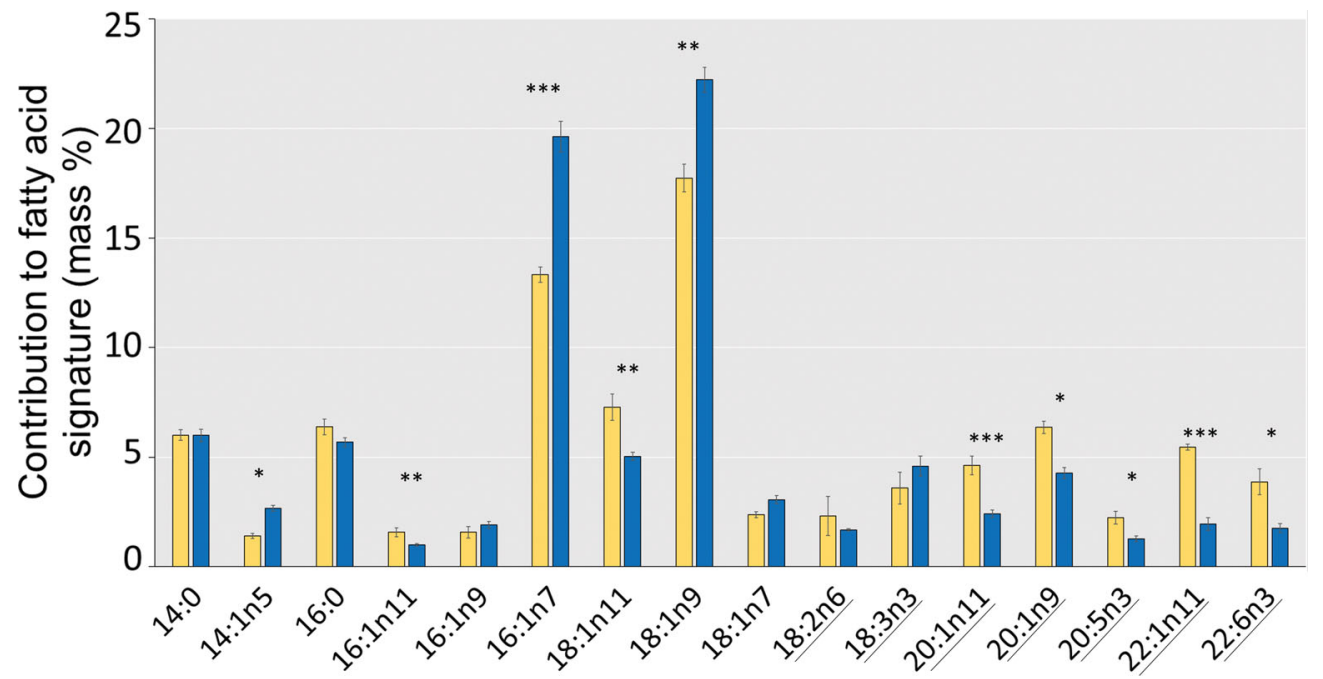

Fig. 1. Mean $( \pm \mathrm{SE})$ overall proportions of the 16 major fatty acids in full-depth blubber sampled from 4 fish-fed, managed-care killer whales (yellow bars) and 19 North Atlantic killer whales from 2005 to 2014 (blue bars). Two North Atlantic fetuses were excluded because the blubber samples were distinct from the blubber of mature animals both visually and by fatty acid signatures. Underlined fatty acids are considered to be primarily or solely derived from dietary intake (Iverson et al. 2004). Significant differences in fatty acid proportions between managed-care and North Atlantic killer whales are denoted by asterisks as follows: ${ }^{*} \mathrm{p}<0.05 ;{ }^{* *} \mathrm{p}<0.01 ;{ }^{* * *} \mathrm{p}<0.001$ 


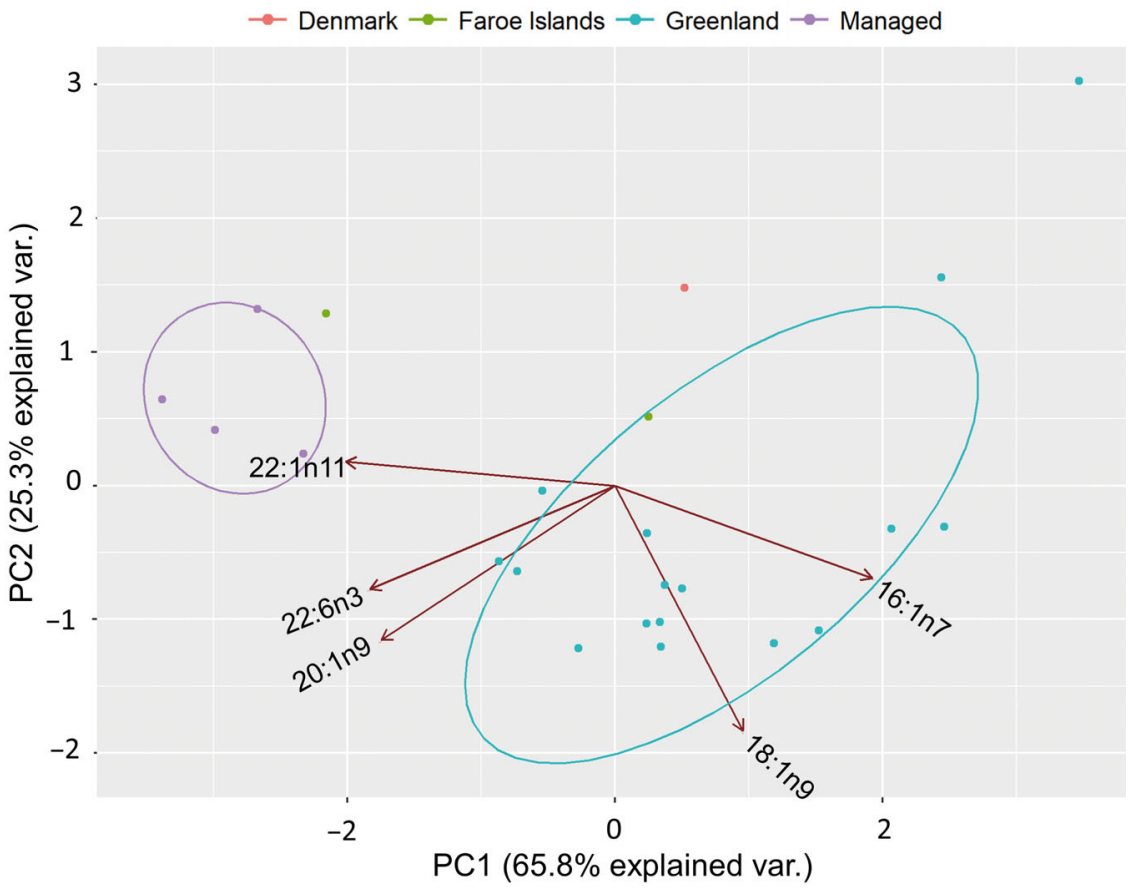

Fig. 2. Loading plot from the principal component analysis (PCA) of fatty acid signatures in full-depth blubber of 19 North Atlantic killer whales sampled between 2005 and 2014 (16 from Greenland in blue, 1 from Denmark in pink, 2 from the Faroe Islands in green) and 4 fish-fed, managed-care killer whales (in purple). Eigenvectors of the 5 fatty acids used in the PCA are shown in brown arrows. Ellipses show 95\% CIs around the Greenland (blue) and managed-care (purple) whales. Samples closer together in the PCA show more similar fatty acid profiles. PC1 and PC2 (displayed) explained $91.1 \%$ of the variance ception was that the single Faroe Islands sub-adult showed a fatty acid signature more similar to the managed-care individuals than to those of the other North Atlantic killer whales. Within the North Atlantic cluster, the Greenland adult male and Greenland sub-adults grouped together, while the Greenland adult females grouped with the Faroe Islands adult female and Denmark newborn. Fatty acid signatures among North Atlantic killer whales also appeared to vary by sex/age class based on PCA (Fig. S1 in the Supplement). The Greenland sub-adults and Greenland adult females separated out into 2 partially overlapping groups based on 95\% CI ellipses. The Greenland adult females showed a relatively tight cluster, while the Greenland sub-adults were more variable; some fell close to the adult females, while others showed very different fatty acid signatures. The male individual from Greenland fell within the sub-adult ellipse.
$18: 2 \mathrm{n} 6(\mathrm{p}=0.302)$ and $18: 3 \mathrm{n} 3(\mathrm{p}=0.367)$ were not significantly different between the 2 groups.

The PCA results showed that the managed-care and Greenland individuals clustered separately (based on non-overlapping $95 \%$ CI ellipses). One individual from the Faroe Islands was situated close to the ellipse of the managed-care individuals, while the other Faroe Islands individual and the Denmark neonate grouped within or close to the Greenland individuals (Fig. 2). The managed-care individuals were positively associated with $22: 1 \mathrm{n} 11,22: 6 \mathrm{n} 3$, and 20:1n9, but negatively with $16: 1 \mathrm{n} 7$ and $18: 1 \mathrm{n} 9$. The Greenland individuals were positively associated $16: 1 \mathrm{n} 7$ and $18: 1 \mathrm{n} 9$, but had more varied weight from the other eigenvectors.

Variation in fatty acid signatures between all North Atlantic and managed-care killer whales, and among sex/age classes, was further investigated by hierarchical cluster analysis (Fig. 3). The greatest separation was between the 2 Greenland fetuses and all other killer whales. The second largest clustering, consistent with the MANOVA and PCA, was based on the managed-care individuals forming a separate group from the free-ranging North Atlantic whales. The one ex-

\section{Fatty acid signature variation with blubber depth}

Stratification of fatty acids through the 10 blubber layers of killer whales was evident based on proportions of the 16 major fatty acids for both the fish-fed, managed-care whales and the free-ranging North Atlantic whales. These 16 fatty acids ranged between $84.60 \%$ (layer 1 closest to the muscle) and $87.80 \%$ (layer 10) of the total mass \% of fatty acids in the managed-care individuals and between $84.59 \%$ (layer 1) and $86.08 \%$ (layer 9) in the free-ranging killer whales. Proportions of 9 (14:0, 14:1n5, 16:1n11, $18: 1 \mathrm{n} 9,18: 3 \mathrm{n} 3,20: 1 \mathrm{n} 9,20: 5 \mathrm{n} 3,22: 1 \mathrm{n} 11$, and $22: 6 \mathrm{n} 3)$ of the 16 major fatty acids in the North Atlantic killer whales varied significantly with depth $(p=0.026)$, including 5 of the 7 dietary fatty acids (Fig. 4A). Blubber of the managed-care individuals showed significant stratification for 12 of the 16 major fatty acids. These included 8 of the 9 (exception was 20:5n3) that showed significant variation with depth for the North Atlantic whales, as well as 16:0, 16:1n9, 16:1n7, and 20:1n11 ( $p=0.035)$ (Fig. 4B)

Post hoc tests showed that variation among layers was mostly due to the innermost layers showing 


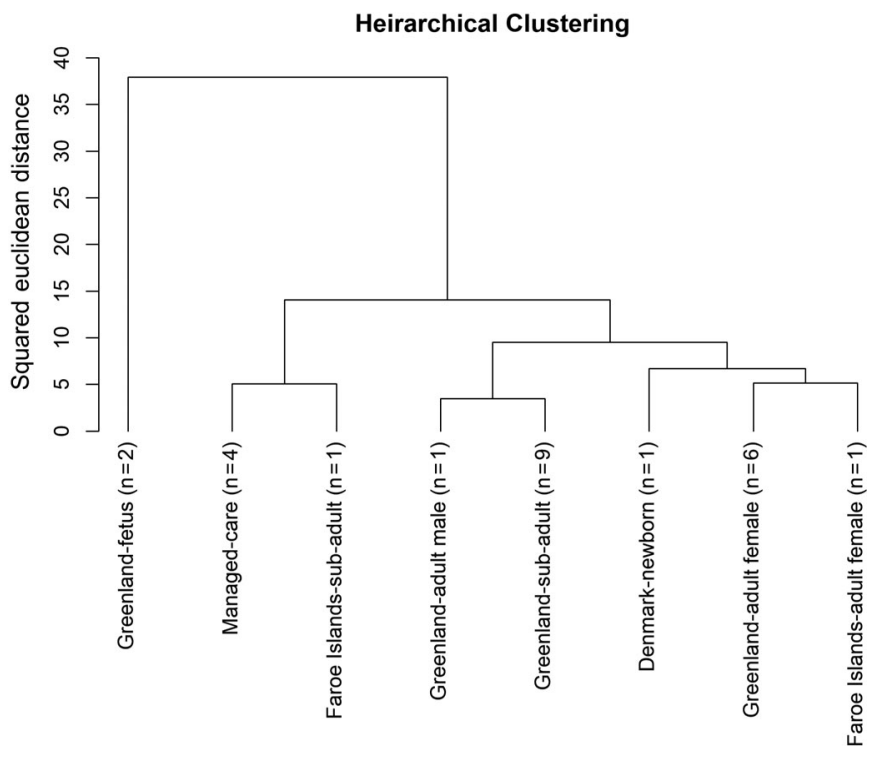

Fig. 3. Hierarchical cluster analysis based on location and demographic group showing the relationship between the average fatty acid signatures for 21 free-ranging North Atlantic killer whales sampled between 2005 and 2014 and 4 fish-fed, managed-care killer whales. Clusters were based on squared Euclidean distances and clustering was created using $k$-means

significant differences from the outermost layers. In both the free-ranging and managed-care killer whales, the major fatty acids were not significantly different among layers 1 through 3, nor among layers 5 through $10(\mathrm{p}<0.05)$. However, fatty acid proportions in layers 1 to 4 often significantly differed from those in layers 5 to 10 . No 2 adjacent layers showed significant differences. Significant differences were found to follow a gradient throughout blubber depth (see Table S3 in the Supplement).
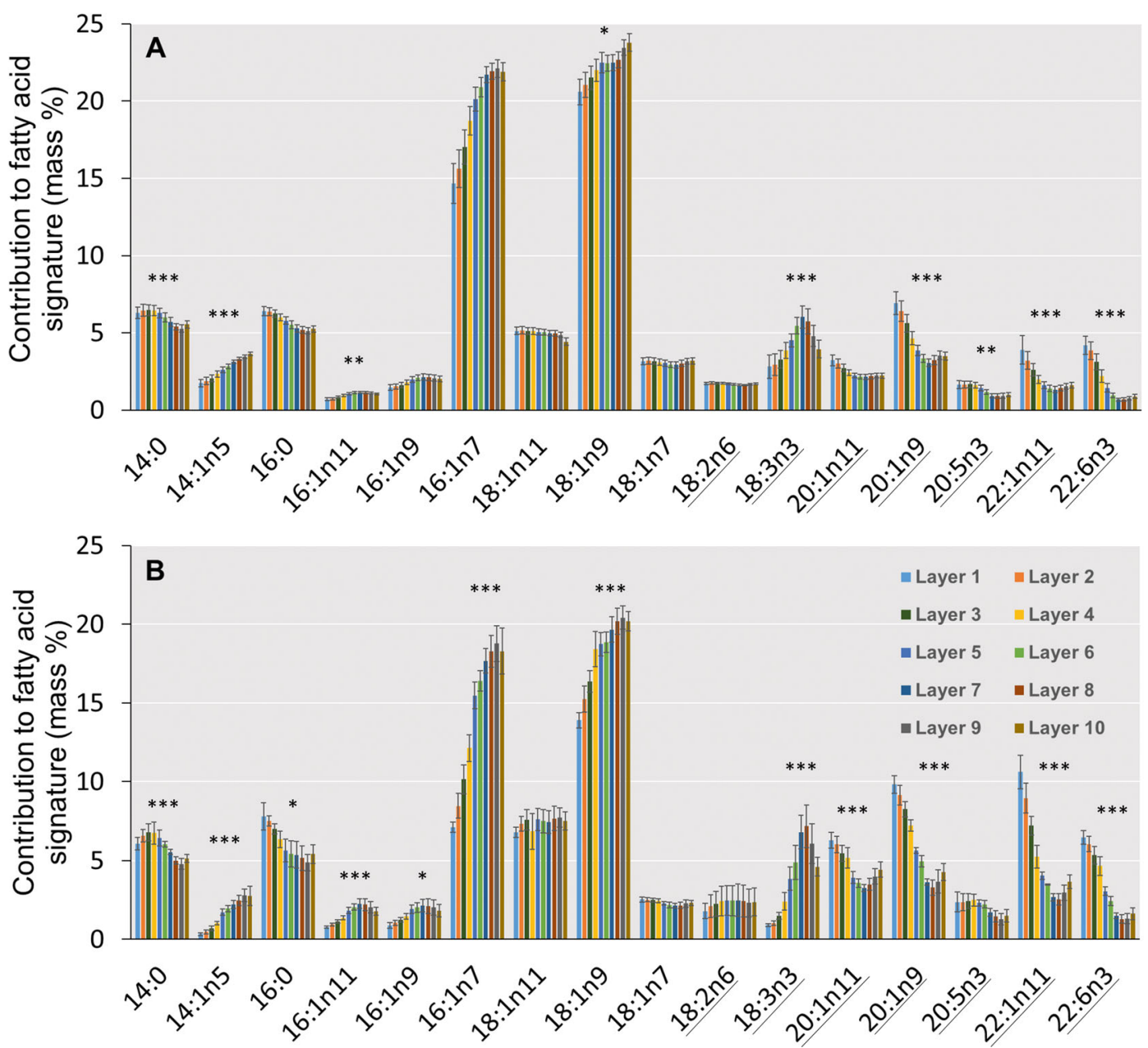

Fig. 4. Mean $( \pm$ SE) proportions of the 16 major fatty acids for each layer in (A) North Atlantic killer whales from 2005 to 2014 $(\mathrm{n}=19)$ and $(\mathrm{B})$ fish-fed, managed-care individuals $(\mathrm{n}=4)$. Two fetuses from the North Atlantic group were excluded because the samples were distinct from the mature blubber both visually and by fatty acid signatures. Underlined fatty acids are considered to be primarily or solely present due to dietary intake (Iverson et al. 2004). Significant differences in fatty acid proportions are denoted by asterisks as follows: ${ }^{*} \mathrm{p}<0.05,{ }^{* *} \mathrm{p}<0.01,{ }^{* * *} \mathrm{p}<0.001$ 

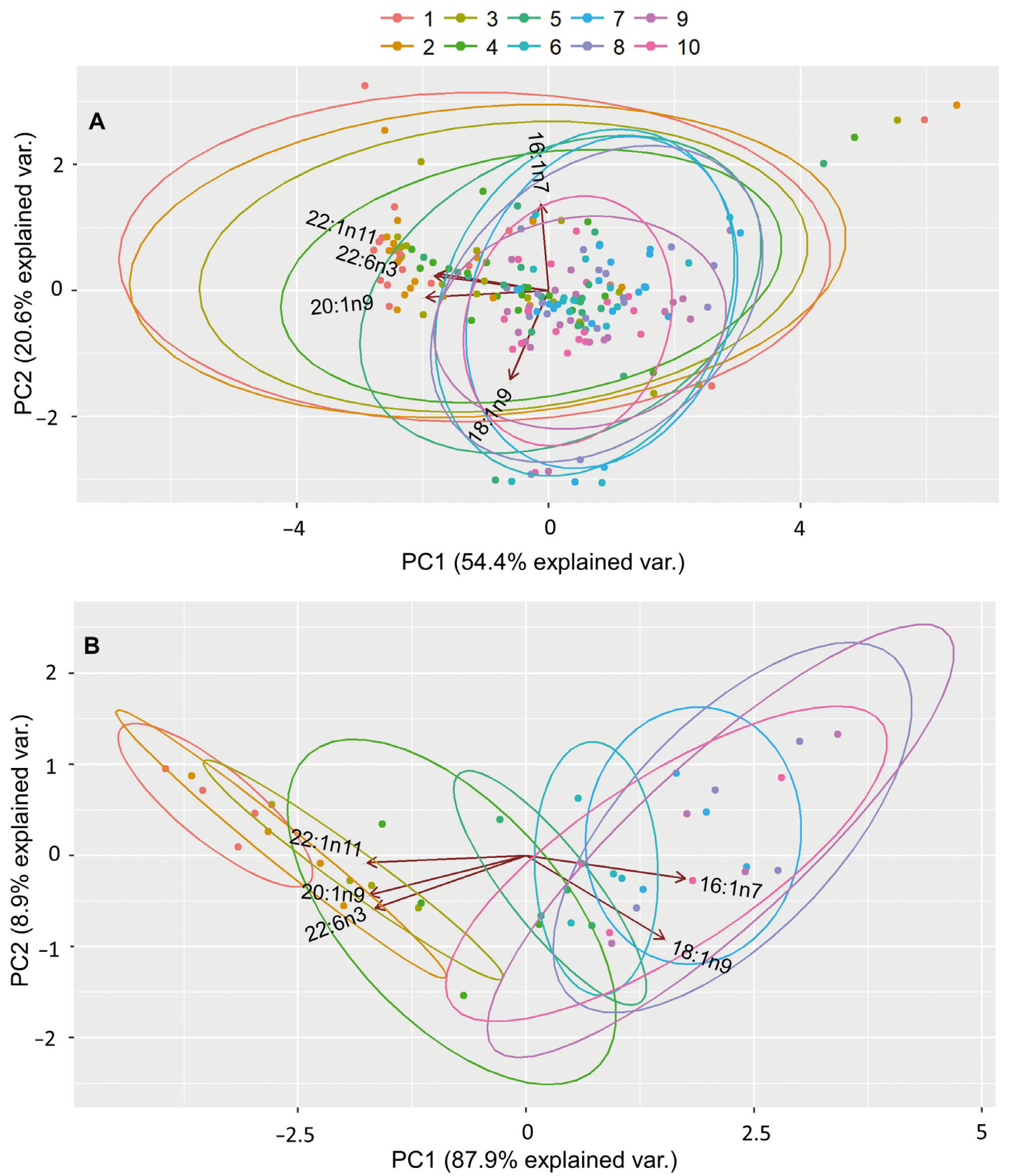

Fig. 5. Principal component analysis (PCA) results for the fatty acid signatures among 10 equal-length blubber sections of (A) 19 North Atlantic killer whales sampled between 2005 and 2014 in Greenland, Faroe Islands, and Denmark, and (B) 4 managed-care killer whales. Eigenvectors for the 5 fatty acids used in the analysis are shown with brown arrows; ellipses denote $95 \%$ CIs. The 2 PCs represent 75.0 and $96.8 \%$ of the variation in the free-ranging and managed-care killer whales, respectively. Eigenvectors for fatty acids 22:1n11 and 22:6n3 in the North Atlantic killer whales overlapped

More detailed examination of variation with blubber depth for the North Atlantic killer whales using PCA showed that fatty acid proportions were most variable among individuals for the inner blubber layers (closest to muscle) and became progressively more similar for the outer blubber layers (closest to the epidermis) (Fig. 5A). The dietary fatty acids 20:1n9, $22: 1 \mathrm{n} 11$, and 22:6n3 loaded negatively on PC1, whereas the fatty acids sourced from a combination of diet and biosynthesis (e.g. 16:1n7, 18:1n9) loaded 
more on PC2. Most of the variation in inner-layer fatty acid signatures among individuals occurred along PC1, and thus was related to the proportions of these primarily dietary fatty acids. Furthermore, the dietary fatty acids showed higher variability in layers 1 through 4 than in the more outer layers.

The PCA considering the 10 blubber layers for the managed-care killer whales appeared to differ from that of the North Atlantic killer whales (Fig. 5B). For the managed-care whales, the inner blubber layers actually showed less variation than the outer layers. Nearly all of the variation (87.9\%) was explained by PC1, on which the primarily dietary fatty acids 22:1n11, 20:1n9, and 22:6n3 loaded negatively, and the other 2 fatty acids (16:1n7 and 18:1n9) loaded positively. Thus, these dietary fatty acids occurred to a greater degree in the inner blubber layers (largely layers 1, 2, 3, and to a lesser extent layer 4), whereas the other 2 fatty acids occurred to a greater degree in the outer layers. The dietary fatty acids in the managed-care individuals also show less variation than in the free-ranging individuals.

Further examination showed that the free-ranging versus managed-care samples were best distinguished by comparing the inner layers (Fig. S2 in the Supplement). The managed-care individuals grouped very closely in layer 1 and only showed slight overlap with the free-ranging individuals. These clusters were more similar in layer 5. By layer 10, the $95 \%$ CI around the managed-care individuals was much larger and partially overlapped with the Greenland individuals. Conversely, the CI around the East Greenland individuals decreased in size from the inner to the outer layers.

\section{DISCUSSION}

\section{Insight into diets of North Atlantic killer whales from fatty acid signatures}

North Atlantic killer whales showed distinct fatty acid signatures relative to fish-fed, managed-care animals, strongly suggesting that their diets are not exclusively fish-based. Significant differences in proportions of specific fatty acids (higher proportions of $14: 1 \mathrm{n} 5$ and $16: 1 \mathrm{n} 7$, and lower proportions of 22:6n3 in North Atlantic versus managed-care killer whales) further suggests that North Atlantic killer whales feed on marine mammals in addition to fish. Similar variation in fatty acid signatures between fishfeeding and marine mammal-feeding killer whales was previously found in ecotypes from the Northeast
Pacific (Herman et al. 2005). Stomach contents of a handful of these North Atlantic individuals did indicate feeding on minke whales Balaenoptera acutorostrata and harp seals Pagophilus groenlandicus (Table 1). Based on the fatty acid signature results, these behaviors are not insolated in time nor to a small subset of the North Atlantic individuals. The divergence from the fatty acid signatures of the fishfed, managed-care killer whales strongly suggests that marine mammals are important to the diets of these northward-redistributing free-ranging North Atlantic killer whales. Further work to develop methods to quantitatively estimate the proportions of fish versus marine mammals in the diets of these killer whales should be undertaken (e.g. Iverson et al. 2004, Bromaghin 2017).

In addition to the managed-care and wild killer whales showing distinct fatty acid signatures, these 2 groups also showed differences in the extent of interindividual variation. The managed-care killer whales formed a much tighter cluster than the North Atlantic killer whales. It could be argued that these results could be explained by inherent variation in fatty acid signatures among demographic groups (GrahlNielsen et al. 2005). However, tight clustering of the fatty acid signatures of the managed-care killer whales was found, despite the group being comprised of a sub-adult female, 2 adult females, and 1 sub-adult male. What all 4 individuals did all have in common was a consistent, long-term diet. This limited variation within the managed-care individuals supports the hypothesis that diet is the major driver of fatty acid signatures in lipid storage tissues such as blubber in killer whales (Koopman 2007). Considering the free-ranging North Atlantic individuals in light of this, the high variability among individuals suggests, perhaps not surprisingly, that these killer whales have substantially higher inter-individual variation in their diets relative to the constant diet of the managed-care whales.

While fatty acid signatures evidently differed among the managed-care and free-ranging North Atlantic killer whales, there was also variation among freeranging killer whales from Greenland relative to those from the Faroe Islands and Denmark. The Greenland whales were distinct from the managedcare whales, while fatty acid signatures of the killer whales from the Faroe Islands and Denmark were intermediate between the Greenland and managedcare whales. This result suggests that the diets of North Atlantic killer whales vary among regions and/or seasonally. In particular, the result is consistent with the hypothesis that marine mammals are an 
important component of the diets of the individuals when in Greenland, but are perhaps not common or not preyed on at all by killer whales in the Faroe Islands and Denmark. Thus, sympatric variation of diet may be occurring amongst pods in the North Atlantic similar to that seen in the Northeast Pacific's different predatory styles of the transient and resident ecotypes (Barrett-Lennard 2000). Not all killer whales in the North Atlantic include marine mammals in their diets, leading to the killer whales in the region also diverging into ecotypes based on dietary specialization (Similä \& Ugarte 1993, Similä et al. 1996, Foote et al. 2009, 2011, 2012, Samarra et al. 2017). Sympatric divergence has been seen through rapid phenotypic changes linked to 2 different foraging strategies in the North Atlantic based on tooth wear and stable isotopes (Foote et al. 2009). These 2 strategies include a 'Type 1 ' that is a generalist predator (suggested to focus on herring and mackerel, but also to consistently consume higher trophic-level prey) and a 'Type 2' that is highly specialized and believed to prey on other cetaceans (perhaps baleen whales). Nonetheless, Foote et al. (2012) identified discrepancies between the stomach contents of killer whales and their tissue nitrogen stable isotope ratios consistent with differences in long-term diets relative to seasonal specialization.

In addition to broad-scale variation in the diets of the North Atlantic killer whales, examination of the fatty acid signatures among just the Greenland killer whales suggests dietary variation among individuals within a single region. This variation appears to be related, at least in part, to demographic group. The PCA results showed that the Greenland adult females formed a small cluster, while the Greenland sub-adults formed a much larger cluster that partially overlapped the adult females. The adult male was located within the sub-adult cluster, but not within the section that overlapped the adult females. It is worth noting that the sex of the subadults was not available, and therefore juvenile male versus juvenile female feeding could not be delineated. These results suggest that diet variation may occur within pods. According to the PCA results, the Greenland adult females tended to show more similar fatty acid signatures to the fish-fed, managed-care killer whales. Conversely, the Greenland adult male and at least some of the sub-adults showed the most different signatures from the fishfed, managed-care individuals. Therefore, it is possible to speculate that the adult females may feed to a greater degree on fish, while the adult males and sub-adults may specialize to a greater degree on marine mammals. The role of demographic variation in delineating between generalist and specialist individuals within pods in the North Atlantic has not been analyzed (Foote et al. 2009). All free-ranging killer whales sampled from 2012 were from the same pod; however, we do not know yet whether all the killer whales from Greenland in other years were part of the same pod. To test whether withinpod demographic variation in feeding habits is occurring, relatedness among individuals within this study will need to be tested via genetic approaches.

\section{Implications of fatty acid stratification in blubber for determining killer whale feeding habits}

Fatty acid variation throughout the layers of blubber was pronounced, but inter-individual variation differed between the free-ranging and managedcare individuals. In the North Atlantic killer whales, the inner blubber layers (closer to muscle) showed higher variance among individuals than the outer layers. Variance decreased moving outward towards the skin. The higher variation in the inner tissues is likely due to large variation in feeding habits among the individual North Atlantic killer whales, as the inner layers have been suggested to be more reflective of recent feeding patterns (Budge et al. 2006). The fish-fed, managed-care killer whales, however, showed a contrasting pattern, whereby the least variation among individuals occurred in the inner layers. This pattern is consistent with the knowledge that their diet was constant over an extended period of time. Even though these results may seem contradictory, they may in fact be complementary. Together, they show that variation amongst the inner layers is primarily driven by the diet. Thus, fatty acid signatures from the inner blubber layers should be examined when evaluating inter-individual or interpopulation similarities or differences in the diets of killer whales, and likely other marine mammals with stratified blubber fatty acid signatures.

Fatty acid variation through blubber depth suggests that the blubber sampling procedure must be considered in fatty acid-based diet analysis. This variation with depth is likely due to the inner layers being more metabolically active and potentially reflecting short-term feeding habits more accurately (Koopman et al. 2002, Koopman 2003, Iverson et al. 2004). For dietary fatty acids, 4 out of the 5 analyzed in the PCA showed decreasing proportions from the inner blubber layers to the outer blubber layers. Thus, the use of traditional biopsies that only sample 
part of the blubber layer may lead to measured fatty acid proportions that are either inflated or deflated compared to proportions from the inner blubber or the mean over the entire blubber depth. When examining specific layers, diet appeared to be best represented by the inner layers. Dietary fatty acids were found to be at highest abundance in the inner layers ( 1 to 4 ) and to decrease steeply through these layers until about layer 5, after which most tended to level off. Fatty acids present from de novo synthesis showed the reverse trend, being more abundant in outer layers, which suggests that factors other than diet are increasingly important in contributing to fatty acid variation towards the outer sections of blubber. These findings are in agreement with a previous study of multiple odontocete species, where inner blubber tissues consistently tended to show higher proportions of dietary fatty acids than the outer layers, while outer blubber layers tended to have higher proportions of endogenous fatty acids (Koopman 2007). Additionally, short-chained monounsaturated fatty acids, e.g. 14:1n5 and 16:1n7, were more abundant in the outer layers than in the inner layers, similar to that seen in a recent study on humpback whales Megaptera novaeangliae (Waugh et al. 2014).

Consequently, we suggest that, if possible, the inner blubber layers or possibly full blubber depth should be utilized for studies of killer whale diets. However, due to the lethality of collecting inner blubber layers, it is only feasible to sample full blubber depth on posthumous and opportunistically sampled killer whales and other cetaceans with stratification of blubber fatty acids. Nonetheless, our results suggest that biopsies that only sample the outer blubber layers may still provide some insight into cetacean diets, though potentially with lower resolvability than using inner blubber or full-depth tissues. In this study, the fish-fed, managed-care individuals were separated from the free-ranging individuals even just considering layer 10 alone, but the separation of the 2 groups was much clearer when examining full-depth and inner blubber layers. These findings point to the inner layers likely being less confounded by physiological variation and thus representing a clearer signal from the diet. That is, fatty acid analysis of biopsies consisting only of outer layers may have not detected more subtle differences in feeding habits among groups. Incongruously, a study on New Zealand sea lions Phocarctos hookeri using QFASA found that fatty acid analysis of the outer blubber layers led to the same diet conclusions as using the inner layers (Lambert et al. 2013). How- ever, the extent of blubber fatty acid stratification among marine mammal species, and the prey on which they feed, varies among marine mammal species, suggesting that the influence of stratification may need to be examined on a per species basis. For killer whales, future work will evaluate the influence of blubber depth on quantitative diet estimates using fatty acid-based approaches.

Acknowledgements. Thanks to local hunters for assistance in the free-ranging killer whale sample collection, as well as J. Weisser, M. Levin, and B. M. Jenssen for participating in the sampling. D. Bloch, E. Stefansson, L. Jensen, and B. Mikkelsen provided blubber samples and biological details of the stranded killer whales from the Faroe Islands and Denmark. Thanks to SeaWorld staff for assistance with the managed-care samples. Thanks to A. Provatas and G. Ulatowski for allowing us to use instruments in their labs and to J. August, C. Boba, and K. Tom for assisting in the analysis. Thanks to R. Pugh and J. Kucklick (NIST) for providing the SRM1945. This research was supported by a 2017 Summer Grant from the Center of Biological Risk at the University of Connecticut, the SeaWorld \& Busch Gardens Conservation Fund, as well as from the University of Connecticut Scholarship Facilitation Fund, and start-up funds (M.A.M.). Additional funds for sample collection in Greenland came from The Danish Cooperation for Environment in the Arctic (DANCEA) Programme (R.D., C.S.), The Carlsberg Foundation, and the European Union Seventh Framework Programme (M.H., grant agreement PIOF-GA-2012-329996).

\section{LITERATURE CITED}

Aitchison J (1983) Principal component analysis of compositional data. Biometrika 70:57-65

Barrett-Lennard LG (2000) Population structure and mating patterns of killer whales (Orcinus orca) as revealed by DNA analysis. PhD dissertation, University of British Columbia, Vancouver

Bowen WD, Iverson SJ (2013) Methods of estimating marine mammal diets: a review of validation experiments and sources of bias and uncertainty. Mar Mamm Sci 29: 719-754

Bromaghin JF (2017) qfasar: quantitative fatty acid signature analysis with R. Methods Ecol Evol 8:1158-1162

*Budge SM, Iverson SJ, Koopman HN (2006) Studying trophic ecology in marine ecosystems using fatty acids: a primer on analysis and interpretation. Mar Mamm Sci 22: 759-801

Budge SM, Springer AM, Iverson SJ, Sheffield G, Rosa C (2008) Blubber fatty acid composition of bowhead whales, Balaena mysticetus: implications for diet assessment and ecosystem monitoring. J Exp Mar Biol Ecol 359:40-46

Cooper MH (2005) Fatty acid metabolism in marine carnivores: implications for quantitative estimation of predator diets. PhD dissertation, Dalhousie University, Halifax

Ferguson SH, Higdon JW, Chmelnitsky EG (2010) The rise of killer whales as a major Arctic predator. In: Ferguson $\mathrm{SH}$, Loseto LL, Mallory ML (eds) A little less Arctic. Springer, New York, NY, p 117-136 
Foote AD, Newton J, Piertney SB, Willerslev E, Gilbert MTP (2009) Ecological, morphological and genetic divergence of sympatric North Atlantic killer whale populations. Mol Ecol 18:5207-5217

Foote AD, Vilstrup JT, De Stephanis R, Verborgh P and others (2011) Genetic differentiation among North Atlantic killer whale populations. Mol Ecol 20:629-641

Foote AD, Vester H, Víkingsson GA, Newton J (2012) Dietary variation within and between populations of northeast Atlantic killer whales, Orcinus orca, inferred from $\delta^{13} \mathrm{C}$ and $\delta^{15} \mathrm{~N}$ analyses. Mar Mamm Sci 28: E472-E485

Ford JKB, Ellis GM, Matkin CO, Wetklo MH, BarrettLennard LG, Withler RE (2011) Shark predation and tooth wear in a population of northeastern Pacific killer whales. Aquat Biol 11:213-224

Grahl-Nielsen O, Halvorsen AK, Bodoev N, Averina L and others (2005) Fatty acid composition of blubber of the Baikal seal Phoca sibirica and its marine relative, the ringed seal P. hispida. Mar Ecol Prog Ser 305:261-274

Herman DP, Burrows DG, Wade PR, Durban JW and others (2005) Feeding ecology of eastern North Pacific killer whales Orcinus orca from fatty acid, stable isotope, and organochlorine analyses of blubber biopsies. Mar Ecol Prog Ser 302:275-291

Higdon JW, Ferguson SH (2009) Loss of Arctic sea ice causing punctuated change in sightings of killer whales (Orcinus orca) over the past century. Ecol Appl 19: 1365-1375

*Higdon JW, Hauser DDW, Ferguson SH (2012) Killer whales (Orcinus orca) in the Canadian Arctic: distribution, prey items, group sizes, and seasonality. Mar Mamm Sci 28: E93-E109

Iverson SJ, Field C, Bowen WD, Blanchard W (2004) Quantitative fatty acid signature analysis: a new method of estimating predator diets. Ecol Monogr 74:211-235

Koopman HN (2003) The structure and function of the blubber of odontocetes. PhD dissertation, Duke University, Durham, NC

Koopman HN (2007) Phylogenetic, ecological, and ontogenetic factors influencing the biochemical structure of the blubber of odontocetes. Mar Biol 151:277-291

Koopman HN, Pabst DA, McLellan WA, Dillaman RM, Read AJ (2002) Changes in blubber distribution and morphology associated with starvation in the harbor porpoise (Phocoena phocoena): evidence for regional differences in blubber structure and function. Physiol Biochem Zool 75:498-512

Krahn MM, Herman DP, Ylitalo GM, Sloan CA and others (2004) Stratification of lipids, fatty acids and organochlorine contaminants in blubber of white whales and killer whales. J Cetacean Res Manag 6:175-189

Krahn MM, Herman DP, Matkin CO, Durban JW and others (2007) Use of chemical tracers in assessing the diet and foraging regions of eastern North Pacific killer whales. Mar Environ Res 63:91-114

Kucklick JR, Schantz MM, Pugh RS, Porter BJ and others (2010) Marine mammal blubber reference and control materials for use in the determination of halogenated organic compounds and fatty acids. Anal Bioanal Chem 397:423-432

Lambert A, Meynier L, Donaldson LC, Roe WD, Morel PCH (2013) Body regional distribution and stratification of fatty acids in the blubber of New Zealand sea lions: implications for diet predictions. J Comp Physiol B 183:
145-156

* McKinney MA, Iverson SJ, Fisk AT, Sonne C and others (2013) Global change effects on the long-term feeding ecology and contaminant exposures of East Greenland polar bears. Glob Change Biol 19:2360-2372

Nordstrom CA, Wilson LJ, Iverson SJ, Tollit DJ (2008) Evaluating quantitative fatty acid signature analysis (QFASA) using harbour seals Phoca vitulina richardsi in captive feeding studies. Mar Ecol Prog Ser 360:245-263

*Pedro S, Boba C, Dietz R, Sonne C and others (2017) Blubber-depth distribution and bioaccumulation of PCBs and organochlorine pesticides in Arctic-invading killer whales. Sci Total Environ 601-602:237-246

R Development Core Team (2016) R: a language and environment for statistical computing. R Foundation for Statistical Computing, Vienna

* Samarra FIP, Vighi M, Aguilar A, Víkingsson GA (2017) Intra-population variation in isotopic niche in herringeating killer whales off Iceland. Mar Ecol Prog Ser 564: $199-210$

Similä T, Ugarte F (1993) Surface and underwater observations of cooperatively feeding killer whales in northern Norway. Can J Zool 71:1494-1499

Similä T, Holst JC, Christensen I (1996) Occurrence and diet of killer whales in northern Norway: seasonal patterns relative to the distribution and abundance of Norwegian spring-spawning herring. Can J Fish Aquat Sci 53: 769-779

N Springer AM, Estes JA, van Vliet GB, Williams TM, Doak DF, Danner EM, Pfister B (2008) Mammal-eating killer whales, industrial whaling, and the sequential megafaunal collapse in the North Pacific Ocean: a reply to critics of Springer et al. 2003. Mar Mamm Sci 24:414-442

Statistics Greenland (2017) Piniarneq - the Greenland catch statistics 1993-2017. Data collected by the Greenland Government. Statistics Greenland, Nuuk

Stevens JP (1986) Applied multivariate statistics for the social sciences. Routledge, New York, NY

Tabachnick BG, Fidell LS (1989) Using multivariate statistics. Harper Collins, New York, NY

Thiemann GW, Iverson SJ, Stirling I (2008) Polar bear diets and Arctic marine food webs: insights from fatty acid analysis. Ecol Monogr 78:591-613

Tollit DJ, Steward MJ, Thompson PM, Pierce GJ, Santos MB, Hughes S (1997) Species and size differences in the digestion of otoliths and beaks: implications for estimates of pinniped diet composition. Can J Fish Aquat Sci 54: 105-119

Tollit DJ, Heaslip SG, Deagle BE, Iverson SJ, Joy R, Rosen DAS, Trites AW (2006) Estimating diet composition in sea lions: Which technique to choose? In: Trites AW, Atkinson SK, DeMaster DP, Fritz LW, Gelatt TS, Rea LD, Wynne KM (eds) Sea lions of the world. Alaska Sea Grant College Program, Anchorage, AK, p 293-307

*Waugh CA, Nichols PD, Schlabach M, Noad M, Bengtson Nash S (2014) Vertical distribution of lipids, fatty acids and organochlorine contaminants in the blubber of southern hemisphere humpback whales (Megaptera novaeangliae). Mar Environ Res 94:24-31

Worthy GA (2008) An investigation into the possible relationship between killer whale (Orcinus orca) predation and the continuing decline of the Steller sea lion (Eumetopias jubatus) population. Report PCCRC FP204077 to the Pollock Conservation Cooperative Research Center, Fairbanks, AK 